Artigos

Volume 10 - $2020 \mid$ n. 13

\title{
A Formulação do PDE-Escola no Contexto do Estado Gerencial e os seus Impactos na Gestão Escolar: uma análise de teses recentes
}

\author{
Girlane Orrico Costa \\ Universidade Federal do Acre (UFAC), Cruzeiro do Sul/AC - Brasil
}

\section{Resumo}

Este trabalho analisa a produção acadêmica recente, em nível de doutorado, sobre a política Plano de Desenvolvimento da Escola (PDE-Escola), apresentando as análises desenvolvidas acerca da formulação desta política no contexto atual, marcado pela penetração do gerencialismo nas políticas educacionais, assim como acerca dos efeitos do PDE-Escola na gestão da escolar. Para tanto, foi realizada uma busca por produções acadêmicas no Catálogo de Teses e Dissertações da Capes. Optou-se pela busca por teses produzidas sobre essa temática em Programas de Educação no período de 2013 a 2017. Buscou-se construir o "estado da questão" da temática abordada, situando no tempo e espaço as produções selecionadas e identificando seus objetivos, referenciais teórico-metodológicos, procedimentos de pesquisa e principais resultados.

Palavras-chave: Gerencialismo. Políticas educacionais. Financiamento da educação. Descentralização da gestão financeira. Gestão escolar.

\section{The Formulation of PDE-School in the Context of the Management State and its Impacts on School Management: an analysis of recent theses}

\begin{abstract}
This paper analyzes the recent academic production, at the doctoral level, on the School Development Plan (PDE-Escola) policy, presenting the analyzes developed on the formulation of this policy in the current context, marked by the penetration of managerialism in educational policies, and on the effects of the PDE-Escola on school management. For that, a search for academic productions was carried out in the CAPES Theses and Dissertations Catalog. We chose to search for theses produced on this theme in Education Programs from 2013 to 2017. We sought to build the "state of the question" of the theme addressed, placing the selected productions in time and space and identifying their objectives, theoretical and methodological references, research procedures and main results.
\end{abstract}

Keywords: Managerialism. Educational policies. Education Funding. Decentralization of financial management. School management. 
A Formulação do PDE-Escola no Contexto do Estado Gerencial e os seus Impactos na Gestão Escolar

\section{Introdução}

O gerencialismo vem se consolidando nas últimas décadas como um importante conceito para a compreensão da estruturação do Estado e da administração pública em diversos países no período recente. A ideologia do Estado gerencial funda-se na prerrogativa de superação da crise do Estado de bem-estar social, sob a promessa de corrigir os problemas da administração burocrática e tornar o Estado mais eficiente, por meio da adoção de uma lógica empresarial e da racionalização dos gastos e práticas governamentais, disseminando o discurso da modernização e a ideologia de que "boas práticas" de gestão devem se basear na mesma lógica do mercado, primando por uma administração focada em resultados, associada a sistemas de controle, metas, monitoramento de desempenho e prestação de contas, via o firmamento de contratos. Tal lógica, atrelada a interesses neoliberais e a teorias empresariais, promove um conjunto de efeitos cascatas sobre os "novos gestores" e às instituições públicas. Entre estes, destaca-se a competição, intensificação do trabalho e autocontrole. Nesse cenário, prega-se a necessidade de o trabalhador se comprometer com a qualidade dos serviços prestados e de se empenhar pela resolução de problemas, tendo como foco os seus clientes (NEWMAN; CLARKE, 2012).

Sob a influência dessa ideologia gerencialista, propalada por organismos internacionais, como o Banco Mundial, são realizadas reformas de Estado e reformas da educação em diversos países do globo. As reformas educacionais globais têm provocado mudanças significativas na forma de conceber a gestão da educação e da escola, promovendo, sob o mote da descentralização e autonomia, um processo de transferência de responsabilidades para as instâncias locais, acompanhada de mecanismos de avaliação e regulação. Essas reformas transformam drasticamente o setor público da educação, mediante incentivos a parcerias com o setor privado, dinâmicas de competitividade entre os sistemas educacionais e a introdução da cultura gerencial do setor empresarial. Promete-se, com essas reformas, elevar a qualidade educacional, mas sem que implique investir mais recursos nos sistemas, implantando uma lógica de otimização de recursos e de custo-benefício e custo-eficiência, que implica em redução de investimento na educação, ao mesmo tempo que se amplia a cobrança por resultados. Assim, essas reformas subestimam os reais problemas da educação e superestimam o papel da escola na resolução desses problemas (VERGER, 2012).

Importa ressaltar que uma das críticas do Estado gerencial ao Estado de bem-estar social diz respeito aos investimentos no setor social. Na perspectiva gerencial, o Estado deve reduzir os seus custos com as políticas sociais, por meio das parcerias com o setor privado e da introdução de mecanismos de planejamento estratégico e cobrança por resultado, alimentando a compreensão de que os problemas da educação não resultam de insuficiência de recursos, mas de uma gestão ineficiente. Não obstante, como afirma Newman e Clarke (2012, p. 358), "Isto introduziu novas lógicas de tomada de decisão que privilegiavam economia e eficiência acima de outros valores públicos", fenômeno que vem afetando profundamente o financiamento e gestão da escola pública.

As políticas educacionais elaboradas nas últimas décadas apresentam marcas expressivas dessa nova lógica da gestão pública. Os princípios gerenciais têm sido condutores da formulação de um conjunto de políticas implementadas no Brasil por diferentes governos no período recente (MISOCZKY; ABDALA; DAMBORIARENA, 2017). Logo, a 
A Formulação do PDE-Escola no Contexto do Estado Gerencial e os seus Impactos na Gestão Escolar

construção das políticas educacionais recentes reflete, em boa medida, a forma de agir do Estado gerencial. Contudo, também importa ressaltar as tensões existentes entre a lógica gerencial e outras lógicas de governo, o que resulta em ações políticas com diferentes nuances. Segundo Maroy (2011), as políticas oriundas dos modelos de governança promovidos por organismos internacionais passam pela condição de recepção nos contextos no quais são processadas, havendo um processo de hibridização dos modelos, definido pela mistura de diferentes lógicas, discursos e práticas na definição e ação da política.

Analisando as reformas educacionais iniciadas no Brasil e nos países latino-americanos na década de 1990, no contexto da reforma do Estado, Oliveira (2011) destaca a influência da demanda popular por participação, por um lado, e, por outro lado, o uso da descentralização pela gestão pública-estatal, resultando em novos modelos de gestão pública descentralizada, sendo a descentralização um dos principais mecanismos da reforma. Nesse cenário, são formuladas e implementadas um conjunto de políticas educacionais que descentralizam recursos federais para as instituições escolares, entre estas, políticas que realizam a transferência direta de recursos financeiros da União para a escola.

A construção das políticas de assistência à educação está prevista na Constituição Federal de 1988, que estabelece, em meio aos deveres da União para com a educação, a função redistributiva do governo federal, por meio da assistência técnica e financeira aos governos subnacionais, entendida como ações públicas baseadas no princípio da equidade, que implica na alocação de um volume maior de recursos para as escolas e as redes em situação relativamente desfavorecida. Na lista das políticas de assistência da União para com a educação, encontra-se, dentre outros, o Programa Dinheiro Direto na Escola (PDDE) (FARENZENA, 2011).

O PDDE, criado em 1995, foi a primeira política de transferência direta de recursos financeiros para a escola, permanecendo em vigor nos diferentes governos desde a sua criação, sobre a prerrogativa de desburocratizar e agilizar o repasse de recursos financeiros federais para as instituições de ensino. A partir de 2004, houve uma expansão das ações vinculadas ao PDDE e, a partir de 2007, com o lançamento do Plano de Desenvolvimento da Educação (PDE), o Ministério da Educação e Cultura (MEC) passou a utilizar a estrutura de execução descentralizada do PDDE para realizar ações específicas. Assim, além do PDDE tradicional, surge um conjunto de políticas de descentralização vinculadas a este programa, entre estas, o Plano de desenvolvimento da Escola, PDE-Escola (MAFASSIOLI, 2017).

Essa política consiste em uma das ações do Plano de Desenvolvimento da Educação, destinada às escolas que apresentam baixo resultado no IDEB. Para o recebimento dos recursos, é exigida das escolas beneficiadas a elaboração de planos estratégicos, com a participação da comunidade escolar e com base nas metas e diretrizes do PDE. Assim, com a ampliação das transferências de recursos federais para as instituições escolares, observase que a escola pública ganha maior centralidade na execução de políticas educacionais e na gestão dos recursos recebidos por meio de tais transferências.

Segundo Oliveira (2011), a ênfase da participação no nível local trouxe novas experiências na gestão pública, demandando maior atenção aos processos de implementação. "O pouco conhecimento desses processos é evidente e tem resultado em maiores esforços da pesquisa acadêmica para ampliar a capacidade de interpretação dessa realidade" (OLIVEIRA, 2011, p. 81). Não obstante, é preciso considerar o fato de que a 
A Formulação do PDE-Escola no Contexto do Estado Gerencial e os seus Impactos na Gestão Escolar

implementação modifica a política, de modo que, no contexto da prática, uma política pode ser ressignificada ou até mesmo refutada pelos sujeitos que interpretam e aplicam esta política. "Um programa é, então, o resultado de uma combinação complexa de decisões de diversos agentes" (ARRETCHE, 2001, p. 47).

Neste trabalho, realiza-se, sob a perspectiva do "estado da questão", um mapeamento da discussão acadêmica recente desenvolvida em nível de doutorado acerca da formulação e implementação do Plano de Desenvolvimento da Escola (PDE-Escola) no contexto de penetração do gerencialismo nas políticas públicas educacionais, considerando as influências presentes na formulação dessa política, oriunda do Plano de Desenvolvimento da Educação (PDE), e os seus efeitos sobre a gestão escolar.

Na construção do "Estado da Questão" o objetivo é situar uma temática no campo da produção bibliográfica existente, com o intuito de revelar ao pesquisador os achados alcançados sobre o seu tema de pesquisa, distinguindo-se da Revisão de Literatura e do Estado da Arte (NOBREGA-THERRIEN; THERRIEN, 2010). Na Revisão da Literatura, buscase construir uma base teórica para a análise de dados. No Estado da Arte, o objetivo é mapear a produção científica em um determinado campo, por meio de uma análise descritiva das produções existentes. Já no Estado da Questão, busca-se mapear as produções acerca de uma temática em um determinado período, a partir de questões específicas. Para a construção deste trabalho, buscou-se responder as seguintes questões acerca da temática pesquisada: quais são os trabalhos e respectivos autores e locais de produção de teses que abordam a temática em questão nos últimos cinco anos? Quais foram os objetivos de estudo dessas pesquisas? Quais foram os referenciais teóricos e metodologias adotadas? Quais foram os achados? E, por fim, como se situam no campo da pesquisa em políticas educacionais? As respostas a essas perguntas estão organizadas em tópicos específicos.

Além desta introdução, este trabalho está organizado em três seções. Na primeira seção, apresenta-se a metodologia utilizada para a busca das produções, os trabalhos encontrados, os seus autores e a localização no tempo e no espaço. Na segunda seção, são apresentados os objetivos, referenciais teóricos e as opções metodológicas das pesquisas. $\mathrm{Na}$ terceira seção, apresentam-se os achados e discutem-se os resultados dos estudos selecionados, seguindo-se das considerações finais.

\section{A metodologia da busca pelas produções e os seus resultados}

Neste tópico, apresenta-se a metodologia adotada para a seleção das produções acadêmicas analisadas neste trabalho, assim como os resultados da busca. A pesquisa foi feita no Catálogo de Teses da Capes, disponibilizado no endereço eletrônico: $<$ http://catalogodeteses.capes.gov.br/catalogo-teses/\#!/>. A princípio, esta pesquisa pretendia também analisar as produções sobre o Programa Dinheiro Direto na Escola. No entanto, ao identificar apenas uma tese sobre este programa no período pesquisado, optouse por limitar a pesquisa às análises sobre o PDE-Escola. Foram utilizados três descritores de busca: nova gestão pública, gerencialismo e PDDE, PDE. Dado o número elevado de resultados encontrados e buscando atender aos propósitos da pesquisa, optou-se pelo refinamento da busca, sendo selecionadas apenas as teses produzidas em Programas de Pós-Graduação em Educação no período de 2013 a 2017. Nesta condição, foi encontrado um total de 1189 resultados, conforme quadro abaixo. 
A Formulação do PDE-Escola no Contexto do Estado Gerencial e os seus Impactos na Gestão Escolar

Quadro 1 - Descritores utilizados para a busca das produções e os resultados

\begin{tabular}{|l|c|c|c|c|c|c|}
\hline \multirow{2}{*}{ Descritor } & \multicolumn{7}{c|}{ Ano } & Total \\
\cline { 2 - 7 } & 2013 & 2014 & 2015 & 2016 & 2017 & \\
\hline Nova gestão pública & 172 & 231 & 224 & 249 & 263 & 1139 \\
\hline Gerencialismo & 06 & 04 & 02 & 09 & 01 & 22 \\
\hline PDE, PDDE & 0 & 09 & 08 & 08 & 03 & 28 \\
\hline
\end{tabular}

Fonte: Elaboração própria.

Para a seleção dos resultados encontrados, adotaram-se os seguintes critérios: mencionar no título, resumo ou palavras-chave as políticas PDE-Escola e/ou PDDE ou, ainda, contextos relacionados a estas políticas e aos seus efeitos na gestão da escola pública. Após aplicar tais critérios e excluir as repetições de resultados, foram selecionadas 11 teses. Como entre estas havia apenas uma tese sobre o PDDE, ela também foi excluída, restando dez teses, apresentadas a seguir.

Quadro 2 - As teses selecionadas em Programas de Educação no período de 2013 a 2017

\begin{tabular}{|c|c|c|c|}
\hline Autor(a) & $\begin{array}{c}\text { Estado } \\
\text { (Instituição) }\end{array}$ & Título & $\begin{array}{c}\text { Ano de } \\
\text { publicação }\end{array}$ \\
\hline $\begin{array}{l}\text { Otávio Cordeiro de } \\
\text { PAULA }\end{array}$ & $\begin{array}{l}\text { Rio de Janeiro } \\
\text { (PUC-RJ) }\end{array}$ & $\begin{array}{c}\text { O Plano de Desenvolvimento da Escola } \\
\text { como instrumento de gestão das escolas } \\
\text { públicas municipais de Campos dos } \\
\text { Goytacazes/RJ }\end{array}$ & 2017 \\
\hline $\begin{array}{l}\text { Veridiana Xavier } \\
\text { DANTAS }\end{array}$ & $\begin{array}{l}\text { Paraíba } \\
\text { (UFPB) }\end{array}$ & $\begin{array}{l}\text { PDE Escola na dimensão do ensino e } \\
\text { aprendizagem no sistema municipal de } \\
\text { ensino de Santa Rita/PB }\end{array}$ & 2017 \\
\hline Albiane Oliveira GOMES & $\begin{array}{l}\text { Pará } \\
\text { (UFPA) }\end{array}$ & $\begin{array}{c}\text { Do plano de escola a escola do plano: } \\
\text { Implicações do Plano de Desenvolvimento } \\
\text { da Escola (PDE-Escola) na qualidade do } \\
\text { ensino nas escolas municipais de São } \\
\text { Luís/MA }\end{array}$ & 2016 \\
\hline $\begin{array}{l}\text { Domingos Pereira da } \\
\text { SILVA }\end{array}$ & $\begin{array}{l}\text { São Paulo } \\
\text { (UNICAMP) }\end{array}$ & $\begin{array}{l}\text { O Plano de Desenvolvimento da Educação } \\
\text { no contexto da terceira via: o neoliberalismo } \\
\text { reconfigurado }\end{array}$ & 2016 \\
\hline $\begin{array}{l}\text { Andréia Vicência Vitor } \\
\text { ALVES }\end{array}$ & $\begin{array}{l}\text { Mato Grosso do } \\
\text { Sul } \\
\text { (UFMS) }\end{array}$ & $\begin{array}{c}\text { As formulações para a gestão da educação } \\
\text { básica no estado de Mato Grosso do Sul em } \\
\text { interseção com as ações da união (1988- } \\
\text { 2014) }\end{array}$ & 2015 \\
\hline $\begin{array}{l}\text { Rita de Cássia } \\
\text { OLIVEIRA }\end{array}$ & $\begin{array}{l}\text { Minas Gerais } \\
\text { (UFJF) }\end{array}$ & $\begin{array}{l}\text { Programas PDE Escola e Mais Educação: } \\
\text { descentralização e gestão do ensino }\end{array}$ & 2014 \\
\hline $\begin{array}{l}\text { Adailda Gomes de } \\
\text { OLIVEIRA }\end{array}$ & $\begin{array}{l}\text { Rio de Janeiro } \\
\text { (PUC-RJ) }\end{array}$ & $\begin{array}{l}\text { O processo de implementação do PDE- } \\
\text { Escola no contexto das políticas de } \\
\text { responsabilização: o caso da cidade do Rio } \\
\text { de Janeiro }\end{array}$ & 2014 \\
\hline $\begin{array}{c}\text { Ana Claudia Celice } \\
\text { Alves VASCONCELOS }\end{array}$ & $\begin{array}{l}\text { São Paulo } \\
\text { (UNESP) }\end{array}$ & $\begin{array}{c}\text { Efeitos da política de avaliação do PDE no } \\
\text { sistema municipal de ensino }\end{array}$ & 2014 \\
\hline $\begin{array}{l}\text { Jean Mario Araújo } \\
\text { COSTA }\end{array}$ & $\begin{array}{l}\text { Bahia } \\
\text { (UFBA) }\end{array}$ & $\begin{array}{c}\text { A política de educação básica brasileira } \\
\text { instituída pelo Plano de Desenvolvimento da } \\
\text { Educação: relações intergovernamentais no } \\
\text { contexto da nova gestão pública }\end{array}$ & 2014 \\
\hline $\begin{array}{l}\text { Vilma Aparecida de } \\
\text { SOUZA }\end{array}$ & $\begin{array}{l}\text { Minas Gerais } \\
\text { (UFU) }\end{array}$ & $\begin{array}{l}\text { O plano de metas "Compromisso Todos pela } \\
\text { Educação": desdobramentos na gestão } \\
\text { educacional local e no trabalho docente }\end{array}$ & 2014 \\
\hline
\end{tabular}

Fonte: Elaboração própria.

Quanto à localização das produções selecionadas, constata-se que, embora haja produções em quase todas as regiões do país, com exceção apenas da Região Sul, o maior 
A Formulação do PDE-Escola no Contexto do Estado Gerencial e os seus Impactos na Gestão Escolar

número de teses foi produzido na região Sudeste, concentrando-se nesta região mais da metade das produções selecionadas.

\section{Os objetivos, as opções teóricas e os percursos metodológicos}

Entre as dez teses selecionadas, três realizaram estudos de cunho bibliográfico e documental para responderem a seus objetivos. Destas, duas dedicam-se à análise dos fundamentos do Programa Plano de Desenvolvimento da Educação (PDE). Silva (2016) buscou apreender a concepção teórica-política deste programa e Costa (2014) apresentou como objetivo analisar os fatores determinantes da política de educação básica brasileira instituída pelo PDE, materializada pelo Plano de Metas Compromisso Todos Pela Educação, focalizando as bases que dão sustento às relações intergovernamentais no contexto da nova gestão pública, com ênfase na educação municipal. Já Alves (2015), por meio de uma análise documental, visou distinguir as formulações governamentais para a gestão da educação básica pública estatal sul-mato-grossense em cada período governamental, entre 1988 a 2014, analisando-as como tradução de relações federativas entre governos de estado e da União.

Outro grupo de trabalhos dedicou-se à análise das repercussões do PDE-Escola na gestão educacional e escolar e os seus efeitos sobre o ensino e o trabalho docente, em diferentes localidades brasileiras. Nesse grupo, incluem-se cinco trabalhos. Nas produções de 2014, foram selecionadas três teses desenvolvidas a partir dessa problemática. Souza (2014) analisa o programa de governo PDE/PMCTE e seus desdobramentos na gestão educacional/escolar pública e no trabalho docente em escolas municipais de um município mineiro, considerando o processo de produção e implementação dessa política e os atores que interferiram em sua elaboração, no contexto da rede de políticas. A pesquisa de Oliveira, R. de C. (2014) visa conhecer os indícios das mudanças ocorridas após a implementação dos Programas PDE-Escola e Mais Educação, no período de 2007 a 2012, em escolas municipais de Juiz de Fora/MG. Já a pesquisa de Vasconcelos (2014) analisa os efeitos da política de avaliação educacional em larga escala do ensino fundamental, implementada a partir da criação do Plano de Desenvolvimento da Educação (PDE) em 2007, no âmbito da gestão da rede municipal de ensino de Araçatuba/SP e de escolas municipais.

Ainda nesse grupo, inclui-se o trabalho de Gomes (2016), cujo objetivo foi analisar as repercussões do PDE-Escola na gestão escolar e suas implicações para a qualidade do ensino em escolas municipais de São Luís/MA. Inclui-se, também, o trabalho de Dantas (2017), que analisou os efeitos do PDE-Escola para o desenvolvimento da gestão escolar no critério de eficácia ensino e aprendizagem do Sistema Municipal de Ensino de Santa Rita/PB, investigando o contexto local nas categorias do Currículo organizado e articulado e Práticas efetivas dentro de sala de aula.

Os demais trabalhos selecionados apresentam objetivos situados em diferentes problemáticas. Oliveira, A. G. de (2014) objetivou analisar o processo de implementação do Programa PDE-Escola no município de Rio de Janeiro, face ao contexto mais recente de políticas do governo federal com perspectiva de responsabilização, nos seus diferentes níveis. No nível macro, analisa-se as etapas de estruturação, negociação e implementação do programa, a partir do Ministério da Educação (MEC) e de agências internacionais. No nível mesopolítico a análise está assentada na estruturação do programa e seu desenvolvimento 
A Formulação do PDE-Escola no Contexto do Estado Gerencial e os seus Impactos na Gestão Escolar

na rede municipal do Rio de Janeiro, através de suas instâncias de mediações (SMERio/CREs/RJ), focalizando como o programa está sendo implementado no município desde 2007 e examinando a participação dos atores sociais nas instâncias de mediações. Já no nível microinstitucional, analisa-se a implementação dos processos técnico-gerenciais e político-financeiros do PDE-escola por unidades escolares participantes do programa.

Já a pesquisa de Paula (2017) lançou como objetivo analisar o planejamento elaborado por escolas municipais de Campos dos Goytacazes/RJ, relacionando os objetivos e problemas identificados por essas instituições com os processos de execução das ações e aplicação dos recursos financeiros, didáticos e pedagógicos para a melhoria do desempenho escolar e também com os resultados obtidos na Prova Brasil. Buscou-se, ainda, desvelar as percepções dos agentes escolares acerca de possíveis mudanças nas formas de gestão e nas ações pedagógicas propiciadas pela adesão ao PDE Escola.

Assim, tendo em vista as problemáticas identificadas, os objetivos que nortearam os trabalhos selecionados foram divididos em cinco grupos, conforme se apresenta a seguir:

Quadro 3 - Agrupamento dos trabalhos por problemas de pesquisa

\begin{tabular}{|c|l|c|}
\hline Grupo & \multicolumn{1}{|c|}{ Problema de pesquisa } & Trabalhos \\
\hline 1 & Análise dos fundamentos teóricos/políticos do PDE. & (SILVA, 2016), (COSTA, 2014) \\
\hline 2 & $\begin{array}{l}\text { Distinção das formulações governamentais para a gestão } \\
\text { da educação básica pública estatal sul-mato-grossense } \\
\text { em cada período governamental, entre 1988 a 2014. }\end{array}$ & (ALVES, 2015) \\
\hline 3 & $\begin{array}{l}\text { Efeitos do PDE-Escola na gestão educacional e escolar, } \\
\text { na qualidade do ensino e no trabalho docente. }\end{array}$ & $\begin{array}{c}\text { Minas Gerais } \\
\text { (SOUZA, 2014) } \\
\text { Juiz de Fora/MG }\end{array}$ \\
& (OLIVEIRA, R. de C., 2014) \\
& Araçatuba/SP \\
& (VASCONCELOS, 2014) \\
São Luís/MA \\
(GOMES, 2016) \\
Santa Rita/PB \\
(DANTAS, 2017)
\end{tabular}

Fonte: Elaboração própria.

Todos os trabalhos selecionados adotaram a abordagem qualitativa. Nos dois primeiros grupos encontram-se os trabalhos desenvolvidos a partir da pesquisa bibliográfica e da pesquisa documental (SILVA, 2016; COSTA, 2014; ALVES, 2015). Os demais trabalhos associaram a revisão de literatura com a pesquisa de campo. O detalhamento acerca do referencial teórico e da metodologia adotada nas pesquisas é apresentado no quadro abaixo.

Quadro 4 - Delineamento teórico e metodológico das pesquisas

\begin{tabular}{|c|c|c|c|}
\hline Trabalhos & $\begin{array}{c}\text { Abordagem teórica } \\
\text { metodológica }\end{array}$ & Principais autores & $\begin{array}{c}\text { Procedimento de } \\
\text { coleta }\end{array}$ \\
\hline (SILVA, 2016) & $\begin{array}{c}\text { Abordagem dialética; } \\
\text { Materialismo histórico. }\end{array}$ & $\begin{array}{c}\text { (GIDDENS, 1999; 2005) } \\
\text { (KOSIK, 2011) }\end{array}$ & $\begin{array}{c}\text { Bibliográfica; } \\
\text { Análise } \\
\text { documental. }\end{array}$ \\
& & $\begin{array}{c}\text { (MARX, 1978; 2013; 2014) } \\
\text { (MONTAÑO, 2003) } \\
\text { (POULANTZAS, 2000) }\end{array}$ & \\
\hline
\end{tabular}


A Formulação do PDE-Escola no Contexto do Estado Gerencial e os seus Impactos na Gestão Escolar

\begin{tabular}{|c|c|c|c|}
\hline & & (SAVIANI, 2007; 2009; 2010) & \\
\hline (COSTA, 2014) & $\begin{array}{c}\text { Análise de política: } \\
\text { Abordagem do Ciclo de } \\
\text { Políticas; } \\
\text { Análise do conteúdo; } \\
\text { Abordagens } \\
\text { neoinstitucionalista e } \\
\text { regulacionista. }\end{array}$ & $\begin{array}{c}\text { (HÖFLING, 2001) } \\
\text { (BOWE; BALL; GOLD, 1992) } \\
\text { (LAVILLE; DIONE, 1999) } \\
\text { (AGUIRRE E MORAES, 1997); } \\
\text { (LIMA, 2005) } \\
\text { (AZEVEDO; GOMES, 2009) } \\
\text { (BARROSO, 2003; 2005) } \\
\text { (OLIVEIRA, 2005) } \\
\text { (MAROY, 2005) } \\
\text { (LESSARD, 2006) }\end{array}$ & $\begin{array}{l}\text { Bibliográfica; } \\
\text { Análise } \\
\text { documental. }\end{array}$ \\
\hline (ALVES, 2015) & $\begin{array}{l}\text { Técnica de análise } \\
\text { documental; } \\
\text { Análise descritiva dos } \\
\text { dados. }\end{array}$ & $\begin{array}{l}\text { (CELLART, 2008) } \\
\text { (ABRUCIO, 2006) } \\
\text { (AZEVEDO, 2002) } \\
\text { (BARROSO, 2005) }\end{array}$ & $\begin{array}{l}\text { Bibliográfica; } \\
\text { Análise } \\
\text { documental. }\end{array}$ \\
\hline (SOUZA, 2014) & $\begin{array}{l}\text { Abordagem dialética; } \\
\text { Metodologia de análise } \\
\text { de redes sociais; } \\
\text { Abordagem do Ciclo de } \\
\text { Políticas. }\end{array}$ & $\begin{array}{c}\text { (SÁNCHEZ GAMBOA, 2008); } \\
\text { (LOPES, 2010) } \\
\text { (MARTELETO, 2001) } \\
\text { (MIZRUCHI, 2006) } \\
\text { (MARTINS, 2009; 2013) } \\
\text { (SAVIANI, 2009) } \\
\text { (SILVA, 2008; LIMA, 2007) } \\
\text { (BALL, 1994; 1995; 1999; 2004; } \\
\text { 2005; 2006; 2010; 2012; 2013) }\end{array}$ & $\begin{array}{l}\text { Análise } \\
\text { documental; } \\
\text { Entrevista. }\end{array}$ \\
\hline $\begin{array}{c}\text { (OLIVEIRA, R. de C., } \\
\text { 2014) }\end{array}$ & $\begin{array}{c}\text { Análise de } \\
\text { implementação de } \\
\text { política; } \\
\text { Análise da trajetória da } \\
\text { política- Ciclo de } \\
\text { políticas. } \\
\end{array}$ & $\begin{array}{c}\text { (BOWE; BALL, 1992) (DYE, 2009; } \\
\text { CONDÉ, 2012) } \\
\text { (LIMA, 1999) } \\
\text { (CURY, 2002) } \\
\text { (DAVIES, 2004) } \\
\text { (ARAÚJO; OLIVEIRA, 2005) } \\
\end{array}$ & $\begin{array}{c}\text { Análise } \\
\text { documental; } \\
\text { Observação; } \\
\text { Entrevista. }\end{array}$ \\
\hline (VASCONCELOS, 2014) & $\begin{array}{c}\text { Abordagem do Ciclo de } \\
\text { Políticas }\end{array}$ & $\begin{array}{c}\text { (BALL, 2004; 2011) } \\
\text { (MAINARDES, 2009) } \\
\text { (MAINARDES et al ,2011) } \\
\text { (MARTINS, 2001) } \\
\text { (FARIA, 2005) (OZGA, 2000) } \\
\text { (AZEVEDO, 2004) } \\
\text { (FARENZENA, 2010) }\end{array}$ & $\begin{array}{l}\text { Análise } \\
\text { documental; } \\
\text { Acesso aos } \\
\text { sistemas } \\
\text { específicos do } \\
\text { MEC. }\end{array}$ \\
\hline (GOMES, 2016) & Abordagem marxista & $\begin{array}{c}\text { (MARX, 1982; 2006) } \\
\text { (KOSIK, 1986) } \\
\text { (GRAMSCI, 1981; 2001; 2005; } \\
\text { 2010; 2012) } \\
\text { (MONTAÑO, 2000) } \\
\text { (MÉSZÁROS, 2007; 2011) } \\
\text { (OLIVEIRA, 2009) } \\
\text { (SANTOS, 2012) }\end{array}$ & $\begin{array}{l}\text { Análise } \\
\text { documental; } \\
\text { Entrevistas. }\end{array}$ \\
\hline (DANTAS, 2017) & $\begin{array}{l}\text { Abordagem do Ciclo de } \\
\text { Políticas; } \\
\text { Estudo de caso. }\end{array}$ & $\begin{array}{l}\text { (BALL, 1989); (BALL, GOLD E } \\
\text { BOWE, 1992); (BALL, 1994); } \\
\text { (BALL, MAGUIRE E BRAUN, 2016); } \\
\text { (STAKE, 2012); (YIN, 2010); } \\
\text { (BOGDAN E BIKLEN, 1994). }\end{array}$ & $\begin{array}{l}\text { Observação } \\
\text { participante; } \\
\text { Entrevista. }\end{array}$ \\
\hline $\begin{array}{c}\text { (OLIVEIRA, A. G. de, } \\
\text { 2014) }\end{array}$ & $\begin{array}{l}\text { Perspectiva dialética na } \\
\text { análise da trajetória da } \\
\text { política }\end{array}$ & $\begin{array}{c}\text { (GAJARDO, 2000) (BROOKE, } \\
\text { 2006; 2012) (ARRETCHE, 2000) } \\
\text { (ALVES, 2007) (BRANDÃO, 2001) } \\
\text { (VELOSO, 2009) } \\
\text { (CORVALÁN, 2006) }\end{array}$ & $\begin{array}{c}\text { Análise } \\
\text { documental; } \\
\text { Entrevistas. }\end{array}$ \\
\hline (PAULA, 2017) & $\begin{array}{l}\text { Análise de } \\
\text { implementação de } \\
\text { política. }\end{array}$ & $\begin{array}{c}\text { (LIMA e D`ASCENZI, 2013) } \\
\text { (ABRUCIO, 2002; 2010) } \\
\text { (KRAWCZYK, 2008; 2009) } \\
\text { (DOURADO, 2007) } \\
\text { (ARRETCHE, 1999; 2003) } \\
\text { (BARROSO, 1996; 2005) }\end{array}$ & $\begin{array}{l}\text { Análise } \\
\text { documental; } \\
\text { Entrevistas. }\end{array}$ \\
\hline
\end{tabular}

Fonte: Elaboração própria. 
A Formulação do PDE-Escola no Contexto do Estado Gerencial e os seus Impactos na Gestão Escolar

Observa-se, nos procedimentos de pesquisa para coleta de dados, a prevalência do uso da análise documental e da entrevista, associada à pesquisa bibliográfica. No referencial teórico-metodológico das pesquisas, nota-se a prevalência da opção dos pesquisadores pela epistemologia dialética, baseando-se em teorias críticas e na abordagem marxista. Notou-se, também, a associação de abordagens para a análise e avaliação das políticas em questão. Destaca-se a decisão dos pesquisadores de analisar os diferentes contextos de trajetória das políticas: contexto de influência/formulação, de produção e da prática. Para tanto, os autores lançaram mão de um referencial teórico-metodológico voltado para esse propósito, sendo recorrente o emprego da abordagem do Ciclo de Política, proposto por Stephen Ball e seus colaboradores.

\section{Os achados das pesquisas}

Neste tópico serão apresentados os resultados das pesquisas, seguindo a ordem do agrupamento apresentado no Quadro 3, conforme os problemas de estudos. As pesquisas bibliográficas e documentais de Silva (2016) e Costa (2014) traçaram as concepções teóricopolíticas do Plano de Desenvolvimento da Escola (PDE) e analisaram os fatores determinantes dessa política. O estudo de Silva (2016) revelou que o PDE fundamenta-se na orientação teórico-política do programa da "terceira via". Para o autor, a introjeção da responsabilização social, presente nesta orientação, se relaciona ao intento do Estado de fazer com que a escola se torne "menos estatal e mais pública", o que vem sendo funcional para a parcial desresponsabilização do Estado estrito e, consequentemente, para sua redefinição, na implementação das políticas públicas.

A partir das contribuições da abordagem neoinstitucionalista e da escola regulacionista, Costa (2014) constatou que as formulações dos organismos internacionais e suas relações com a atuação empresarial do país demonstraram intensa influência nas políticas educacionais, em especial, na formulação do PDE/ Plano de Metas, considerando que estas políticas se preocupam muito mais em fortalecer o poder regulatório da União sobre os sistemas de ensino do que, propriamente, com uma substancial cooperação entre os entes federativos para o alcance dos objetivos educacionais, como um esforço do Estado. A esse respeito, conclui:

A relação entre os entes federados no PDE é consubstanciada por um movimento híbrido caracterizado por uma interligação entre Estado e mercado em que descentralização, regulação, supervisão, acompanhamento e responsabilização tornam-se, nessa perspectiva, indispensáveis para dar condições ao Estado de desempenhar o seu novo papel. A lógica vigente nesta política aproxima-se menos das questões propriamente educativas e mais da busca por uma governabilidade pública, ungida pela adoção de técnicas de gestão do setor privado, neste caso, enfatizando o desempenho das organizações públicas e o controle da gestão por meio de resultados quantificados, sem a preocupação com os processos e as metodologias com que são executadas as ações (COSTA, 2014, p. 191).

Costa (2014) tece, ainda, as suas conclusões acerca dos desafios da educação brasileira diante de tal cenário:

[...], destaca-se que o grande desafio da atual agenda federativa brasileira, no setor educação, consiste na construção de mecanismos institucionais de coordenação e cooperação que incluam Estados e Municípios não apenas na operação dessas 
A Formulação do PDE-Escola no Contexto do Estado Gerencial e os seus Impactos na Gestão Escolar

políticas, mas na elaboração de proposições que sejam mais equitativas em relação à distribuição de responsabilidades e competências educacionais (COSTA, 2014, p. 191).

Após analisar as formulações para a gestão da educação básica no estado de Mato Grosso do Sul, no período de 1988 a 2014, Alves (2015) chega à conclusão de que houve significativas diferenças entre as proposições dos vários governos, sendo que alguns priorizaram a gestão democrática da educação na formulação das políticas educacionais voltadas para a gestão da educação básica, como os governos de José Orcírio Miranda dos Santos e de Pedro Pedrossian, outros a tornaram questão secundária, como os governos de Marcelo Miranda de Souza e de Wilson Barbosa Martins, e o governo de André Puccinelli a ressignificou, apresentando-a conciliada a critérios de meritocracia e desempenho educacional. Em suas análises, o autor constatou que a gestão gerencial é uma prática em ascensão no âmbito da política educacional nacional e do estado sul-mato-grossense e que a mesma tem ressignificado os mecanismos da gestão democrática, sob uma ótica economicista e preceitos neoliberalizantes, tendo em vista a busca por adequação da educação a padrões internacionais, voltados para o desempenho escolar e o alcance de resultados, cenário no qual a gestão democrática tornou-se uma questão secundária.

Alves (2015) constatou que, tanto em âmbito nacional como no âmbito do estado sulmato-grossense, a gestão da política educacional tem caráter burocrático, autoritário, centralizador e hierárquico, dado o fato de o financiamento e as decisões a respeito das ações educacionais nacionais continuarem centralizados nas mãos da União e as iniciativas de âmbito estadual sul-mato-grossense continuarem concentradas nas mãos do governo estadual. Em sua análise, a autora chega à seguinte conclusão:

Em suma, Mato Grosso do Sul apesar de implementar ações específicas no intento de atender às especificidades de seus alunos, materializou as iniciativas elaboradas e pensadas pelo MEC, que assumiu o papel de articulador, normatizador, avaliador, coordenador e financiador do sistema de ensino sul-mato-grossense, por meio do PDE, do PAR e do Ideb. Com isso, o MEC passou a exercer a função de regulador e monitorador das ações materializadas nas escolas por ele elaboradas, na busca da eficiência, da eficácia e do desempenho educacional (ALVES, 2015, p. 246).

As pesquisas dedicadas à análise dos efeitos do PDE-Escola na gestão escolar, qualidade do ensino e no trabalho docente, inclusas no grupo 3 do Quadro 3, apresentam, em comum, a conclusão de que esta política tem provocado mudanças significativas na gestão da escola pública, afetando também a rotina e condições do trabalho de gestores e professores, sem uma real garantia da elevação da qualidade da educação. A esse respeito, importa apresentar as conclusões de Souza (2014), segundo a qual o PDE/Plano de Metas Compromisso Todos pela Educação materializou no "chão das escolas" uma "qualidade às avessas", trazendo efeitos perversos à política local e ao trabalho docente, em decorrência da lógica da responsabilização/accountability, que instaurou consensos adequados à ordem econômica globalizada para atender aos diferentes interesses em jogo. Uma "qualidade" que, segundo a autora, centra-se na performatividade da escola e de seus profissionais, ao mesmo tempo que se mantêm inalteradas as condições materiais e objetivas de trabalho na instituição escolar.

Após analisar em que medida o PDE/PMCT, como parte de uma rede de políticas, conseguiu implementar os avanços prometidos, Souza (2014) conclui que as ações implementadas por essa política não conseguiram romper essencialmente com o atual status 
A Formulação do PDE-Escola no Contexto do Estado Gerencial e os seus Impactos na Gestão Escolar

quo da política educacional, em decorrência da reprodução da rede de políticas constituídas entre o global e o local, o que, na conclusão da autora, evidencia um cenário de embates e disputas na formulação das políticas educacionais, comprometendo, assim, o protagonismo do Estado. No contexto local, no entanto, não se constatou processos significativos de oposição a essas políticas. Analisando os depoimentos de professores e gestores acerca do PDE-Escola, a autora constatou que, embora tenham sido registradas algumas reclamações sobre a política, estas não foram acompanhadas por processos de resistência. Gomes (2016) também destaca a existência de poucos indícios de resistência a essa política. A partir dos depoimentos dos sujeitos pesquisados por essa autora, ela concluiu que a política tem sido executada sem movimentos de oposição.

Ainda sobre esse contexto, Souza (2014, p. 307) conclui:

O PDE-Escola conseguiu instalar-se no cotidiano da escola como um dispositivo que passou a nortear a gestão escolar, em substituição ao Projeto Político-Pedagógico. $O$ PDE-Escola conseguiu sobrepor-se ao Projeto Político-Pedagógico, prevalecendo uma perspectiva de gestão que descarta a base política inerente ao PPP, e fortalece o viés tecnicista do PDE. Com isso, o PDE-Escola conseguiu deixar sua marca na gestão na escola, sendo absorvido nas escolas como um planejamento inquestionável.

Oliveira, R. de C. (2014) concluiu que, sob o argumento de levar assistência técnica e financeira ao município, a União centraliza as políticas para o ensino fundamental, processo, contraditoriamente, camuflado no município pela capilarização das ações da União nas escolas, em revelia da competência do estado de atuar para o fortalecimento dos sistemas de ensino locais. Constatou-se que, para receber os repasses de recursos da União, as escolas foram impelidas a criar estratégias para resolução de problemas trazidos pela política da União, fragilizando a autonomia dessas instituições. Nesse contexto, a autora apontou como desafio o reconhecimento da condição de "poder" na instituição escolar que, embora percebida, ainda não se inscreve em uma perspectiva participativa capaz de induzir mudanças a partir da escola, sobretudo pela atuação dos profissionais da educação nos processos de planejamento nas escolas e nos órgãos do poder público.

Após ter analisado efeitos do PDE-Escola para o desenvolvimento da gestão escolar no critério de eficácia ensino e aprendizagem, Dantas (2017) conclui, por intermédio das vozes dos sujeitos pesquisados, que há efeitos positivos e negativos dessa política. Entre os efeitos positivos, a autora destaca a autonomia financeira e pedagógica, a reorganização e a aplicação de recursos de forma correta. Como ponto negativo, ressalta o aumento de trabalho e recursos insuficientes, além da falta de envolvimento por parte de alguns. Mesmo diante dos efeitos negativos percebidos, a autora apresenta uma leitura positiva da política analisada, frente às falas dos sujeitos, tecendo a seguinte conclusão: "Assim, percebemos que o PDE Escola vem para somar as ações da escola. Portanto, a pesquisa nos revela, com base nas falas analisadas, que a gestão escolar é democrática e participativa quando se refere ao contexto dos resultados/efeitos" (DANTAS, 2017, p. 140).

A mesma autora conclui, também, que as ações do PDE-Escola foram colaboradoras para a elevação dos índices da escola pesquisada. E, ainda, infere que há um alinhamento entre as avaliações realizadas em sala de aula e o plano de aula dos professores, o que considera como uma política em ação, apontando para a articulação nas ações trabalhadas 
A Formulação do PDE-Escola no Contexto do Estado Gerencial e os seus Impactos na Gestão Escolar

pela escola, compreendendo que são os profissionais da educação os atores nessa arena de pressão por resultados, nos momentos de atuação/encenação, tradução e interpretação.

Vasconcelos (2014), após analisar os efeitos da política de avaliação educacional em larga escala implementada pelo PDE em 2007 na gestão da rede municipal de ensino e de escolas de Araçatuba/SP, apresentou uma conclusão contrária à de Dantas (2017), constatando que "[...] as ações contempladas no PDE, no âmbito deste município, propiciaram mudanças pouco relevantes na organização da escola e, consequentemente, na melhoria dos resultados" (VASCONCELOS, 2014, p. 126). Esse fato, na interpretação de Vasconcelos (2014), conduz à reflexão quanto à efetividade dessas ações. A autora observou, também, que o processo de avaliação interno da rede promoveu maior aproximação da gestão municipal com a gestão da escola, o que não se observou em relação às políticas focalizadas temporárias, como o PDE-Escola e o Programa Mais educação, por estas se apresentarem de forma desalinhada com a gestão local e por se distanciarem do objetivo propagado oficialmente: elevação do desempenho dos alunos.

A respeito da repercussão do PDE-Escola na melhoria da gestão escolar e de suas implicações para a melhoria da qualidade do ensino, Gomes (2016) concluiu que as políticas educacionais, ao tomarem como parâmetro de qualidade tão somente o Índice de Desenvolvimento da Educação (IDEB), deixam de considerar a complexidade da educação, não levando em conta processos indispensáveis para o alcance da qualidade educacional, entre esses a democratização da gestão escolar. Nesse sentido, a pesquisa do autor apontou que o PDE-Escola tem contribuído menos para a democratização da gestão das escolas e mais para a responsabilização dos sujeitos escolares pelos resultados desta instituição. Assim, o autor conclui que a qualidade da "Escola do Plano" está subsumida pela qualidade indicista do "Plano de Escola", "[...] que tem primado por uma qualidade da educação assente em mecanismos de ajustes aos interesses do grande capital, e com isso legitimado a escola de qualidade como privilégio" (GOMES, 2016, p. 267).

Após a apresentação dos resultados desse grupo de pesquisas, apresentam-se os achados das demais pesquisas, que buscaram respostas para questões mais pontuais. Oliveira, A. G (2014), após ter analisado o processo de implementação do PDE-Escola no município de Rio de Janeiro em diferentes níveis de execução da política, apresenta os seus achados. No contexto macro, a autora apresenta os resultados sobre a trajetória de formulação da política:

[...], o PDE-Escola passou por diferentes mudanças metodológicas e operacionais. No entanto, ao longo de toda a sua trajetória manteve a coexistência das lógicas gerencial e da responsabilização na definição do programa. Neste respeito, a análise mostrou que houve uma evolução no modelo gerencial subjacente ao programa. Inicialmente, o PDEEscola utilizava uma lógica fundamentada principalmente nas técnicas gerenciais e, gradativamente, começou a dar maior enfoque à perspectiva da responsabilização e aos conceitos de transparência e participação política. Com efeito, os resultados indicaram que o PDE-Escola assumiu os pressupostos da responsabilização pelo resultado, em consonância com a política mais ampla do governo federal (OLIVEIRA, A. G., 2014, p. 250).

No que tange ao contexto mesopolítico, a autora apresenta os resultados da análise das configurações assumidas pelo programa no município do Rio de Janeiro. 
A Formulação do PDE-Escola no Contexto do Estado Gerencial e os seus Impactos na Gestão Escolar

Os resultados encontrados indicaram que, em linhas gerais, os técnicos incorporaram o discurso da responsabilização pelos resultados na sua atuação junto ao PDE-Escola e junto à própria escola. $O$ fato de o programa infundir elementos da responsabilização em sua execução, atrelado à existência de políticas de responsabilização na rede pareceu favorecer a aceitação do programa e a lógica subjacente ao mesmo. Na visão dos técnicos, as escolas têm que prestar contas de seu desempenho. Os dados apontaram ainda a presença de um comitê ativo na rede. [...]. Por outro lado, vemos que os técnicos se deparam com uma grande sobrecarga de tarefas; e, paralelamente a isso, vem ocorrendo a redução de investimentos federais na capacitação dos técnicos e dos gestores escolares, o que pode comprometer a qualidade do trabalho junto às escolas (OLIVEIRA, A. G., 2014, p. 250-251).

A respeito do contexto da prática, nas escolas que implementaram o programa, a autora conclui:

Os dados apontaram que, em linhas gerais, de fato, as escolas PDE-Escola, em 2011, apresentam desempenho inferior, em termos de processos institucionais, em relação às escolas não participantes do programa. [...]. No entanto, também foi possível verificar a sistemática e contínua melhora entre elas, ainda que em proporções modestas; o que indicou que a tendência da situação educacional dessas escolas é de crescimento. Embora não tenha sido factível inferir se tais melhorias decorreram da implementação do plano, pontuou-se que há que se considerar que o programa responsabilizou as escolas e seus atores, mobilizando todos os atores escolares em prol do processo de ensino aprendizagem, o que pode ter contribuído, bem como pode vir a contribuir, para a melhoria da qualidade da educação das escolas em longo prazo (OLIVEIRA, A. G., 2014, p. 253).

A pesquisa de Paula (2017), com base na análise do planejamento elaborado pelas escolas e da relação deste com as ações, aplicação de recursos e resultados, aponta que a elaboração do PDE-Escola nas instituições pesquisadas não resguardou os passos iniciais requeridos pelo programa para a organização do ambiente institucional, que envolve o planejamento com a participação da comunidade escolar, destacando-se a não efetivação do convite ao Conselho Escolar para elaborar o plano ou constituir um Grupo do Trabalho com a comunidade escolar e a falta de divulgação junto à comunidade escolar do planejamento da escola. Os planos revelam uma forte canalização dos recursos do programa para ações de infraestrutura, sendo quase inexistente ações de resposta aos problemas pedagógicos. Assim, o autor compreende que a aplicação do PDE-Escola nas instituições investigadas no município de Campos dos Goytacazes não envolveu os elementos teórico-metodológicos do planejamento estratégico, e ainda, que os princípios da descentralização, participação institucional e autonomia das instituições escolares foram vivenciados por meio de um planejamento meramente formal.

\section{Considerações finais}

As pesquisas analisadas neste trabalho oferecem importantes contribuições para a compreensão da formulação e implementação da política Plano de Desenvolvimento da Escola (PDE-Escola), atrelada ao Plano de Desenvolvimento da Educação (PDE), seja no apontamento dos fundamentos teórico-políticos dessas políticas, seja na análise dos seus efeitos nos diferentes contextos em que estas são executadas, especialmente no contexto da escola pública, onde se verificou os seus reflexos sobre a gestão escolar, o trabalho docente 
A Formulação do PDE-Escola no Contexto do Estado Gerencial e os seus Impactos na Gestão Escolar

e os resultados de desempenho. Entre os fundamentos apresentados como norteadores da política em análise, destacou-se a prevalência dos princípios neoliberalizantes, com a introdução da lógica da "terceira via" e das estratégias gerenciais, em consonância com um movimento global de reforma da educação, que visa submeter a educação aos princípios de mercado, adequando-a às necessidades da nova configuração capitalista. Entre os reflexos dessas políticas, destaca-se o processo de centralização de decisões e descentralização da execução; regulação e controle da União sobre os governos subnacionais e sobre a escola; a intensificação do trabalho dos sujeitos envolvidos nos processos de execução das políticas e a responsabilização dos sujeitos e instituições executoras pelos resultados.

Entre as análises dos efeitos dessas políticas na escola, destaca-se que somente Dantas (2017) apresenta uma interpretação mais positiva dos impactos observados, considerando as ações do PDE-Escola colaboradoras para a melhoria do desempenho dos alunos, mesmo registrando os efeitos negativos dessa política, apontados pelos sujeitos pesquisados. Os demais trabalhos dedicados à análise/avaliação do PDE-Escola, tecem críticas mais contundentes sobre as ações de tal política, ressaltando a relação desta com os interesses hegemônicos e os seus efeitos nocivos para o trabalho docente, para a construção da gestão democrática e, consequentemente, para a qualidade do ensino e aprendizagem. Em comum, todos os pesquisadores afirmam que, mesmo essa política tendo incrementado os recursos financeiros destinados às escolas, estes ainda são insuficientes para a garantia da qualidade social da educação.

As análises sobre a formulação das políticas em diferentes governos (ALVES, 2015) e sobre a execução das políticas em diferentes contextos (OLIVEIRA, A. G. de, 2014) chamam a atenção sobre a relevância de se considerar o papel das instituições e dos diferentes sujeitos nos processos de formulação, interpretação e execução das políticas, abrindo espaço para reflexões acerca das relações entre a União e governos estaduais no regime federativo brasileiro, assim como as relações dos entes federados com a escola, considerando, neste processo, o papel das instituições de mediação, como as Secretarias de Educação. Tais relações demonstraram-se relevantes para a compreensão da trajetória das políticas analisadas. Observou-se que, para tanto, torna-se também relevante a adoção de um referencial teórico-metodológico que sustente tais análises. Nas teses selecionadas destacouse o uso da abordagem do Ciclo de Políticas proposta por Stephen Ball e seus colaboradores, associadas ou não a outras abordagens e teorias, o que resultou em diferentes formas de organização teórica e de tratamento dos dados apresentados nestas pesquisas.

Diante do exposto, apresenta-se aos pesquisadores da educação o desafio de expandir as investigações acerca das políticas de descentralização de recursos federais para a escola pública, utilizando, para tanto, um percurso teórico-metodológico que sustente a análise das complexas relações existentes nesse processo, tendo em vista o aprofundamento dessa temática no campo das pesquisas em políticas educacionais.

\section{Referências}

ALVES, A. V. V. As formulações para a gestão da educação básica no estado de Mato Grosso do Sul em interseção com as ações da união (1988-2014). 285 f. Tese (Doutorado em Educação) - Centro de Ciências Humanas e Sociais, Universidade Federal de Mato Grosso do Sul, Campo Grande, 2015. 
A Formulação do PDE-Escola no Contexto do Estado Gerencial e os seus Impactos na Gestão Escolar

ARRETCHE, M. T da S. Uma contribuição para fazermos avaliações menos ingênuas. In: BARREIRA, M. C. R. N.; CARVALHO, M. C. B. de (Org.). Tendências e perspectivas na avaliação de políticas e programas sociais. São Paulo: IEE/PUC, 2001. p. 45-56.

COSTA, J. M. A. A política de educação básica brasileira instituída pelo Plano de Desenvolvimento da Educação: relações intergovernamentais no contexto da nova gestão pública. 217 f. Tese (Doutorado em Educação) - Faculdade de Educação, Universidade Federal da Bahia, Salvador, 2014.

DANTAS, V. X. PDE escola na dimensão do ensino e aprendizagem no sistema municipal de ensino de Santa Rita/PB. 215 f. Tese (Doutorado em Educação) - Centro de Educação, Universidade Federal da Paraíba, João Pessoa, 2017.

FARENZENA, N. Políticas de Assistência Financeira da União no Marco das Responsabilidades (Inter)governamentais em Educação Básica. In: GOUVEIA, A. B.; PINTO, J. M. R.; CORBUCCI, P. R. (Org.). Federalismo e Políticas Educacionais na Efetivação do Direito à Educação no Brasil. Brasília: IPEA, 2011. p. 95-110.

GOMES, A. O. Do plano de escola à escola do plano: implicações do Plano de Desenvolvimento da Escola (PDE-Escola) na qualidade do ensino nas escolas municipais de São Luís/MA. 293 f. Tese (Doutorado em Educação) - Instituto de Ciências da Educação, Universidade Federal do Pará, Belém, 2016.

MAFASSIOLI, A. da S. Programa Dinheiro Direto na Escola: (Re)formulações e implicações na gestão escolar e financeira da educação básica (1995-2015). 328 f. Tese (Doutorado em Educação) - Faculdade de Educação, Universidade Federal do Rio Grande do Sul, Porto Alegre, 2017.

MAROY, C. Em direção a uma regulação pós-burocrática dos sistemas de ensino na Europa? In: OLIVEIRA, D. A.; DUARTE, A. (Org.). Políticas Públicas e Educação: regulação e conhecimento. Belo Horizonte: Fino Traço, 2011.

MISOCZKY, M. C.; ABDALA, P. R. Z.; DAMBORIARENA, L. A Trajetória Ininterrupta da Reforma do Aparelho de Estado no Brasil: Continuidades nos Marcos do Neoliberalismo e do Gerencialismo. Administração Pública e Gestão Social, v. 9, n. 3, p. 184-193, 2017.

NEWMAN, J.; CLARKE, J. Gerencialismo. Educação \& Realidade, Porto Alegre, v. 37, n. 2, p. 353-381, maio/ago. 2012. Disponível em: <http://www.ufrgs.br/edu_realidade>. Acesso em: 05 out. 2018.

NÓBREGA-THERRIEN, S. M.; THERRIEN, J. O estado da questão: aportes teóricosmetodológicos e relatos de sua produção em trabalhos científicos. In: FARIAS, I. S. de; NUNES, J. B. de C.; NÓBREGA-THERRIEN, S. M. Pesquisa científica para iniciantes: caminhando no labirinto. Fortaleza: EdUECE, 2010.

OLIVEIRA, A. G. de. O processo de implementação do PDE-Escola no contexto das políticas de responsabilização: o caso da cidade do Rio de Janeiro. $297 \mathrm{f}$. Tese (Doutorado em Educação) - Departamento de Educação, Pontifícia Universidade Católica do Rio de Janeiro, Rio de Janeiro, 2014. 
A Formulação do PDE-Escola no Contexto do Estado Gerencial e os seus Impactos na Gestão Escolar

OLIVEIRA, D. A. As políticas públicas em educação e a pesquisa acadêmica. In: OLIVEIRA, D. A.; DUARTE, A. (Org.). Políticas Públicas e Educação: regulação e conhecimento. Belo Horizonte, MG: Fino Traço, 2011.

OLIVEIRA, R. de C. Programas PDE Escola e Mais Educação: descentralização e gestão do ensino. 355 f. Tese (Doutorado em Educação) - Faculdade de Educação, Universidade Federal de Juiz de Fora, Juiz de Fora, 2014.

PAULA, O. C. de. O Plano de Desenvolvimento da Escola como instrumento de gestão das escolas públicas municipais de Campos dos Goytacazes-RJ. 193 f. Tese (Doutorado em Educação) - Departamento de Educação, Pontifícia Universidade Católica do Rio De Janeiro, Rio de Janeiro, 2017.

SILVA, D. P. O Plano de Desenvolvimento da Educação no contexto da terceira via: o neoliberalismo reconfigurado. $143 \mathrm{f}$. Tese (Doutorado em Educação) - Faculdade de Educação, Universidade Estadual de Campinas, Campinas, 2016.

SOUZA, V. A. de. O plano de metas "Compromisso Todos pela Educação": desdobramentos na gestão educacional local e no trabalho docente. $343 \mathrm{f}$. Tese (Doutorado em Educação) - Faculdade de Educação, Universidade Federal de Uberlândia, Uberlândia, 2014.

VASCONCELOS, A. C. C. A. Efeitos da política de avaliação do PDE no sistema municipal de ensino. 139 f. Tese (Doutorado em Educação) - Faculdade de Filosofia e Ciências, Universidade Estadual Paulista Júlio de Mesquita Filho, Marília, 2014.

VERGER, A. Globalización, reformas educativas y la nueva gestión del personal docente. Revista Docencia, n. 46, p. 4-13, maio 2012.

Girlane Orrico Costa é doutoranda em Educação, pela Universidade Federal do Paraná. Professora da Universidade Federal do Acre.

ORCID: http://orcid.org/0000-0003-0888-8115

E-mail: laneorrico@hotmail.com

Recebido em 28 de fevereiro de 2019

Aprovado em 18 de abril de 2019 


\section{Editores do volume 10}

Márcia Aparecida Jacomini - Universidade Federal de São Paulo, Brasil

José Marcelino de Rezende Pinto - Universidade de São Paulo, Brasil

\section{Comitê Editorial}

Nalú Farenzena - Universidade Federal do Rio Grande do Sul, Brasil

Juca Gil - Universidade Federal do Rio Grande do Sul, Brasil

Theresa Adrião - Universidade Estadual de Campinas, Brasil

Ângelo Ricardo de Souza - Universidade Federal do Paraná, Brasil

\section{Conselho Editorial}

\section{Alejandro Morduchowicz}

Universidad Pedagógica, Provincia de Buenos Aires, Argentina

Andréa Barbosa Gouveia

Universidade Federal do Paraná, Brasil

Fernanda Saforcada

Universidade de Buenos Aires, Argentina

Jacques Velloso

Universidade de Brasília, Brasil

João Monlevade

Senado Federal, Brasil

Jorge Abrahão de Castro

Instituto de Pesquisa Econômica Aplicada / IPEA, Brasil

Lisete Regina Gomes Arelaro

Universidade de São Paulo, Brasil

Luis Carlos Sales

Universidade Federal do Piauí, Brasil

Luiz de Sousa Junior

Universidade Federal da Paraíba, Brasil

Luiz Fernandes Dourado

Universidade Federal de Goiás, Brasil

Magna França

Universidade Federal do Rio Grande do Norte, Brasil

Marcos Edgar Bassi

Universidade Federal de Santa Catarina, Brasil

Maria Angélica Pedra Minhoto

Universidade Federal de São Paulo, Brasil

Maria Beatriz Luce

Universidade Federal do Rio Grande do Sul, Brasil

Maria Dilnéia Espíndola Fernandes

Universidade Federal de Mato Grosso do Sul, Brasil

Nelson Cardoso do Amaral

Universidade Federal de Goiás, Brasil

Nicholas Davies

Universidade Federal Fluminense, Brasil

Robert E. Verhine

Universidade Federal da Bahia, Brasil

Romualdo Portela de Oliveira

Universidade de São Paulo, Brasil

Rosana Gemaque Rolim

Universidade Federal do Pará, Brasil

Rubens Barbosa de Camargo

Universidade de São Paulo, Brasil

Theresa Adrião

Universidade Estadual de Campinas, Brasil

Tristan McCowan

University of London, Reino Unido

Vera Jacob

Universidade Federal do Pará, Brasil

Vera Peroni

Universidade Federal do Rio Grande do Sul, Brasil

Vitor Henrique Paro

Universidade de São Paulo, Brasil

\section{Equipe editorial}

Apoio ao Comitê Editorial: Caio Cabral da Silva

Diagramação, Revisão de português e normalização: Edson Leonel de Oliveira

Revisão de inglês: Sabrina Ferreira

Fineduca - Revista de Financiamento da Educação

Associação Nacional de Pesquisa em

Financiamento da Educação

e-mail: revista.fineduca@gmail.com | site: http://seer.ufrgs.br/fineduca 